\title{
Erratum to: Journal report card
}

\section{Judit Bar-Ilan}

Published online: 22 June 2012

(C) Akadémiai Kiadó, Budapest, Hungary 2012

\section{Erratum to: Scientometrics DOI 10.1007/s11192-012-0671-3}

Since the original publication of the article, the author would like to inform the readers that concept of the "2 year synchronous h-index for journals" was first introduced by Liang and Rousseau (2009) and wishes to add the reference given below.

\section{Reference}

Liang, L., \& Rousseau, R. (2009). A general approach to citation analysis and an h-index based on the standard impact factor framework. In B. Larsen \& J. Leta (Eds.), Proceedings of ISSI 2009 (pp.143-153).

The online version of the original article can be found under doi:10.1007/s11192-012-0671-3.

J. Bar-Ilan $(\bowtie)$

Department of Information Science, Bar-Ilan University, Ramat Gan 52900, Israel

e-mail: Judit.Bar-Ilan@biu.ac.il 